\title{
Power and Pedagogy: Learning for Reflective Development Practice
}

\section{Jethro Pettit}

\section{Introduction}

... a woman stands in the middle of the room, her arms outstretched. Two other women are trying to sculpt her body into a different position, but each time her limbs are moved she moves them rigidly back into the same position. The sculptors soon despair at being able to re-shape the person, and give up. 'It can be very difficult or impossible to change someone else', one woman later explains, 'if that person does not themselves want to change ...'

\begin{abstract}
... four women sit in a circle holding hands and playing a children's game. One goes out, and the others continue to play. Then the fourth returns holding a wrapped gift, but collapses on the floor while delivering it. 'My brother went to the market to get me a gift, but on his way home he was shot by a soldier. He made it home but died after handing me the gift ...'
\end{abstract}

\footnotetext{
... a man stands trembling with sticky tape over his mouth and eyes, while two other men move his limbs about and take turns posing for snapshots in front of him. 'When I saw the photographs of prisoner abuse in Iraq', one later explained, 'I felt it in my body, as if it was happening to me...'
}

These dramatised scenes about personal experiences of power and powerlessness are from a training workshop in Beirut with non-governmental organisation (NGO) leaders from the Middle East and North Africa (MENA). Coming from organisations in Egypt, Iran, Iraq, Jordan, Lebanon, Libya, Palestine, Syria, Turkey and Yemen, the participants worked on issues such as human rights, women's empowerment, street children, reproductive health, refugee resettlement and earthquake relief. They had been invited by a
Lebanese university to attend a course on 'the challenges of participation and governance in the MENA region'. Within this, two facilitators (Peter Taylor and myself) from the Institute of Development Studies (IDS) led a workshop on 'meanings and methods of participation, power and empowerment'.

As can be imagined from the scenes they chose to represent, and from the challenging issues and contexts in which they were working, the participants had no shortage of direct experience with issues of power in their lives. Inevitably, power dynamics also surfaced within the workshop, around differences in perspective on gender, religion, culture, politics and national identity, not to mention the geopolitical 'elephants in the room' - myself and my colleague as facilitators of American and British origin, with support from European donors. But we also found much common ground, and despite (or perhaps even aided by) our differences, a setting of mutual trust and communication was created for exploring issues of power and participation.

\begin{abstract}
What does it mean to learn about power in development work? How can those who are trying to bring about social justice and equitable development in their societies, such as voluntary and public sector workers, learn about power in ways that will help them act more effectively? How can they appreciate some of the more embedded and internalised forms of power (as discussed throughout this IDS Bulletin), and learn to shift the ways in which power reproduces itself within themselves and society?
\end{abstract}

The answers are not simple. From my own experience as a practitioner and teacher, and in my educational work with colleagues at IDS (StackpoolMoore et al. 2006; Taylor and Fransman 2004), we 
have found enormous value in using a range of learning methods in order to engage with the multiple dimensions and practical implications of power. Yet within higher education, and in development studies, the learning process at times seems incomplete. Approaches to conceptual learning are quite advanced, but are not complemented with sufficient inquiry into personal experience, context and practice, except perhaps through more formal analysis of case studies.

In this article, I explore the links between multidimensional concepts of power and the ability of pedagogical approaches from adult education, action research and reflective practice to enable learning about these dimensions. I suggest that if power is socially embedded and internalised, then diverse learning approaches are required to grasp it. Two ideas about 'learning about power' are especially worth considering. One is the need to pay closer attention to the self through methods of reflective practice - even if this runs against some conventions of scientific rigour and objectivity (Moon 2004; Bolton 2001). The second is the need for learning methods that encourage students to cycle and iterate between their lived experience and diverse activities of reflection, expression, conceptualisation and practical action (Kolb 1984; Heron 1999).

For example, in the workshop in Beirut, we began with personal and group reflection on direct experience, using creative writing, storytelling and drama to recreate key moments of power and powerlessness. Participants then analysed their experiences using conceptual explanations of power, and then applied this reflection and analysis to real life situations during field visits in Lebanon. Such cyclical approaches to learning, commonly used in adult education (and increasingly making their way into higher education), could be brought more directly into development teaching and practice. This is especially so if learners hope to engage with power in all of its complexity, as many theorists suggest they should.

This article begins with a personal reflection on who I am, and why I have looked at power as a pedagogical challenge. I then ask what is missing from approaches to learning and teaching about power within higher education and development studies. I go on to highlight some concepts of power, notably the ways in which it can be socially embedded and internalised, and ask what this means for how we might learn about it. I follow this by drawing on principles of adult learning, action research and reflective practice to suggest ways in which experiential and cyclical approaches can enhance learning about these dimensions of power. I then return to the workshop in Beirut to illustrate the connections between power and pedagogy, and conclude by looking at the potential of 'learning for reflective practice' as a means of shifting power in the world of international development.

\section{Why a pedagogy of power?}

Who am I, and why do I look at power from an educational perspective? My various identities, as they are commonly labelled, imply vast degrees of power. I am a white Anglo-American male, middleclass and well educated, teaching in a respected British research institute. By most accounts, these public forms of my identity, as well as my private roles of husband and father, suggest multiple forms of power, shaping who I am and how others may perceive me. But beyond these surface identities, there is also the important question of how I am. I see myself as caring and compassionate, with a deep concern for upholding human dignity, social justice and the interrelatedness of life. I try to approach the world with love and responsibility, seeking to connect with people and the environment in ways that may transcend or transpose certain realities of power - including those implied by the surface identities listed above. I endeavour to learn, albeit imperfectly, how to live in greater empathy and solidarity with people from different backgrounds, cultures and with different material resources, and to exist in deeper balance and interdependence with the natural world.

These values have taken me on a life journey of social activism, philosophical inquiry and spiritual practice. Yet in all of the various activities I have immersed myself in - from opposing nuclear technology and warfare, to fighting the causes of poverty, sexism, racism and other oppressions, to raising my children, practising meditation, tending my garden or walking in the mountains - I have noticed that dominant forms of power in society are terribly slow to change. Yes, we may succeed in affirming the principles and good intentions of change, in proclaiming new ideals and legislating alternatives. But the pervasive power behind social and 
environmental injustice often seems immovable. We do not easily progress from our ideological or conceptual prescriptions to changing our behaviour and practice, or 'walking the talk'.

My own life is full of contradictions and incongruences, like flying in aeroplanes for holidays, owning a second home, and catching myself enacting (often mindlessly) the myriad socially determined power-behaviours expected of me as a professional, a teacher, a husband, a father, a consumer. These are not things that I can easily change, but I can make a start by becoming more aware of them and of how they may reproduce norms of power, for better or worse. In practice, it is not easy to shift the ways power is embodied within me, but I have noticed that attending to micromoments of mindful, reflective practice are important. As an educator, I am interested, therefore, in how I can better facilitate 'learning about power', particularly for those working as change agents. Can a more multidimensional, inquiring and self-aware approach to learning, teaching and practice lead to more enduring changes in power within society?

\section{Teaching and learning about power}

As social scientists, we have long been concerned with understanding power relations, and with preparing ourselves and others with concepts and skills that can be used to address inequalities and make the world a fairer place. Development studies, for example, aims to connect theory with recommendations for policy and practice, and to strengthen the capacities of professionals to use their knowledge to improve the well-being of poor and excluded people. Part of this process involves understanding how power works in society, whether as a productive or oppressive force. How does power shift and evolve, and which interventions will help or hinder progressive social and political change? In development, the operation of power is a central concern, even where the language of power is not explicit.

Yet how well are development workers prepared to understand and address power in their day-to-day work? There are two main limitations evident in the way power is usually approached in development. One is our tendency to examine how power functions 'out there' in wider society, politics and organisations, often in cultures or communities other than our own. Attention is usually given to expressions of power or powerlessness in other people's lives, with some exceptions such as certain forms of gender analysis and participatory research. We avoid looking critically at our own experiences of power, and at how these are shaped by our identities, values and worldviews.

In certain professions, critical reflection on the ways in which power is manifest in our own lives and professional practice are becoming more common. Methods of 'first person inquiry' (Reason and Bradbury 2001; Marshall 2001) and reflective practice (Moon 2004; Bolton 2001) are now more widely known and promoted in education, health and public sector management. Adult education has also long been recognised and innovated with methods of critical reflection and consciousness raising (Freire 1970; Rogers 2003; Mezirow et al. 2000). But in development studies and teaching, beyond important innovations in feminism and participatory research, reflection on the meaning of one's own power and agency is not very common.

A second limitation is that we tend to privilege conceptual and cognitive sense-making above other ways of knowing. While the intellect is a vital instrument of learning, we tend to invest in its growth to the exclusion of other forms of knowledge (Heron 1999; Heron and Reason 2001). Even the idea of critical reflection on our assumptions and worldviews, as advocated by adult educators (e.g. Mezirow et al. 1990 and 2000), is often viewed primarily as a cognitive process of selfdiscovery and transformation; if we can become aware of our mental constructs, we can intentionally revise them. Yet, if power is all-pervasive and multidimensional, as many theorists contend, and is embedded and internalised in our lives, we need more creative methods of learning to grapple with the ways in which power operates. These methods may include creative writing, storytelling, drama, movement and visual arts, and can be combined with analytical and conceptual processes to deepen our capacities for social analysis and critical selfawareness in addressing issues of power.

\section{Multiple dimensions of power}

What do concepts of power tell us about the way in which power can be learned and taught? While there is no consensus on how best to conceptualise power, many would agree that power exists in ways that go beyond the visible or wilful coercion of one 
person or group by another. Much debate about power in recent decades has been about how power is more than an expression of agency and intent, and is to be found in socially and culturally constructed norms, values, behaviour and ways of relating. Others seek to bridge the agency and structure divide, seeing power as mutually reinforced between them. The purpose here is not to find the correct meaning of power, but to draw out the implications for learning about multiple forms of power. One point quickly becomes clear: if we accept that power is multidimensional, defined by various forms of agency and socialisation, then the learning process should enable us to access, explore and understand as many of these dimensions as possible.

There are some who hold firmly to the idea of power as agency, as something that is used by some to influence the actions of others. Steven Lukes (1974/2005), with his idea of 'the three faces of power' is essentially an advocate of 'power over' within the political science debates about who wins or loses in decision making. He adds to the notion of power either being about visible control over decision making (the first face), or about hidden agenda-setting and mobilisation of bias (the second face), by proposing a 'third face of power' related to the shaping of people's wants and needs so that some decisions do not even need to arise. Yet for Lukes, even this third face assumes a wilful intent on the part of the powerful to manipulate the thoughts of the powerless. Power remains an expression of agency, wielded by those who have it over those who do not.

John Gaventa, in this IDS Bulletin, takes the 'third face' somewhat further with the idea of 'a third form of power, in which conflict is more invisible, through internalisation of powerlessness, or through dominating ideologies, values and forms of behaviour'. This 'invisible power' need not be limited to intentional acts of 'thought control' by the powerful, but can also be self-reproducing social processes in which the thinking and behaviour of the powerful and the powerless are equally conditioned by pervasive norms. Similarly, James Scott's idea of 'hidden transcripts' recognises that the dominant as well as the weak are often caught within the same web of socialised roles and behaviour, often fulfilled without conscious intent (Scott 1992).

Gaventa's 'power cube' (this IDS Bulletin) suggests, therefore, the need for appropriate change strategies when engaging with invisible or internalised power. This third face of power is likewise seen by Lisa VeneKlasen and Valerie Miller (2002) as a barrier to effective citizen participation, and requiring well-designed tactics for building selfawareness, self-esteem and 'power within' to challenge dominant social norms such as gender biases and racism. Their practical approach is grounded in experiences of feminist organising and women's empowerment, and recognises a causal link between gendered norms in society and the fragile condition of women's (or other marginalised people's) 'power within' (VeneKlasen and Miller 2002). Methods are suggested for challenging and reshaping social norms from below, through consciousness raising and self-awareness leading to forms of 'alternative power' as a basis of advocacy and claiming rights. As Harris and Chambers both note (this IDS Bulletin), there are additional implications for encouraging the reflexivity and selfawareness of the powerful as a strategy for changing 'invisible' power.

For some, the 'three faces' concept is too bound up in the assumption that power is a form of agency. Cynthia Hayward (1998, as noted by Boser and Taylor in this IDS Bulletin), argues for 'de-facing power', suggesting that it is misleading to view power as an instrument wielded with conscious intent by the powerful to limit the freedom of the powerless. This shifts attention unduly from the ways we are all socialised into our identities, choices and actions, determining our limits of freedom. For Hayward, power is not a means of control, but 'a network of social boundaries that constrain and enable action for all actors' (1998: 2). Rather than worrying so much about who has or does not have power, she proposes that we focus on 'whether the social boundaries defining key practices and institutions produce entrenched differences in the field of what is possible' (1998: 20). Like other post-structural perspectives on power, Hayward argues for critical examination not of actors and their actions, but of the established social norms, values and assumptions, which constitute power relations.

Foucault's post-modern views on power also lead us away from the idea of actors using power as an instrument of coercion, and point instead to the ways in which 'power is everywhere', diffused and embodied in knowledge and 'regimes of truth', and is what makes us who we are (Foucault 1991; 
Rabinow 1991). Some find Foucault's concept of power so discursive and removed from agency that there seems to be no scope for practical action, but he has been hugely influential in reminding us of the ways that structure can be so embedded as to be beyond our perception - causing us to discipline ourselves without any wilful coercion from others. Bourdieu's view of power does not separate agency and structure, with his idea of 'habitus' as a set of socialised dispositions that shape our actions, and 'doxa' as the taken-for-granted assumptions not questioned or acknowledged by discourses (Gaventa 2003; see Navarro, Taylor and Boser, and Moncrieffe in this IDS Bulletin, for further exploration of Bourdieu).

So if power is everywhere and internalised within us, beyond even our ability to see or challenge its operation in our lives and relationships, what are the implications for how we should teach and learn about power in development practice? Is it enough to know this conceptually, or can we deepen our grasp as a means of engagement?

\section{Multiple dimensions of learning}

In the mainstream of higher education, at least in development studies, students are taught about concepts and asked to apply them to their experiences or case studies. At times this works well, but at other times not because the original analysis was based on a completely different context, or because the case study is superficially treated as a means of illustrating the concept. Theories are enormously useful, if not essential, but how do we avoid the trap of advancing abstract theories in search of empirical cases that will support them? There is a risk of getting caught in theoretical debate without enough grounding in experience. Even transformative approaches to adult education tend to rely on the learner gaining fresh analytical perspectives on his/her worldview as a means of empowerment. Critical reflection is seen as a process of deconstructing and constructing our mental maps. Yet, as powerful as this process can be for the learner, it does not necessarily lead to change.

What I would like to suggest, building on theories of learning and knowledge developed by adult educational theorists such as Kolb (1984), Heron (1999), Rogers (2003), Freire (1970) and others is that understanding and addressing power calls for more innovative learning processes, which stimulate not only the conceptual and rational re-evaluation of one's assumed perspective, but also more the experiential, embodied, creative, practical and other non-dialogical means of reflection, of making sense of one's experiences of power, and of realising one's capacity to shift power.

The experiential learning theories of David Kolb (1984), influenced by Piaget, Lewin and Dewey, and widely adapted by others have been used in education at all levels, not limited to traditions of transformative learning. The basic idea is that learning will be more effective if it cycles through stages of concrete experience, reflection and observation, abstract conceptualisation and active experimentation; and that we all have preferred 'styles' of learning which tend to fall into one or two of these areas: feeling, watching, thinking and doing (Honey and Mumford 1986). Some of us learn best by doing, and then reflecting and drawing out conceptual meaning, while others prefer to develop their conceptual understanding before acting. There are also endless nuances and variations in between these, and the cycles are not necessarily linear or circular. But the point is that there are forms of learning, and therefore of knowledge, which are experiential, embodied or practical, and often nonverbal in expression.

John Heron (1999) follows a similar approach with his four-fold approach to knowledge and learning, or 'extended epistemologies'. The bulk of our knowledge is experiential and learned in affective ways, through living and acting. We also make sense of things with our imaginations, and may represent this 'presentational knowledge' in artistic or nondialogical forms. Conceptual learning and the 'propositional knowledge' it produces, usually associated with formal education and teaching, is vital but is not the only form of knowledge. Finally, there is our tacit learning or 'practical knowledge', the things we know how to do without having to think about it. Heron suggests that we make sense of the world through all of these forms of knowledge, but are grounded in the experiential (more so than we may assume) and move through the presentational, propositional and practical forms in the way our knowledge develops and is expressed (Heron 1999). His thinking is aligned with the notion of tacit and explicit knowledge, and the movement between them. While conceptual or 'propositional' 
Table 1 NGO workshop on power and participation in Beirut

Learning activity

(a) Learning cycle/style (Kolb 1984)

(b) Extended epistemology (Heron

1999)

1 The participants were asked to recall a personal experience of power, or a feeling of being powerless or empowered, and to write about this in a creative way, using their own language and including rich narrative, dialogue, the senses and feeling. They shared their stories in small groups, and selected one story to enact using body sculpture, drama or movement. The other participants were asked to respond to each enactment, mainly to discuss feelings arising rather than to give an analytical interpretation. This took an entire morning. (a) Reflective observation

(b) Presentational knowledge
2 Formal exposition of some conceptual frameworks about power, emphasising that concepts of power are highly contested, and that these were 'tools for thought' rather than truths, which we could use to help make sense of experience. The frameworks included the 'three faces of power' (Gaventa, this IDS Bulletin; Lukes 1974), 'power as knowledge' or 'power is everywhere' (Foucault 1991), 'power over', 'power to', 'power with' and 'power within', and feminist concepts of 'public', 'private' and 'intimate' power (VeneKlasen and Miller 2002). (a) Abstract conceptualisation

(b) Propositional knowledge
3 'Dominator' exercise (Chambers 2002) involving pairs of people one who is in a dominant position of power and the other subservient. They change seating positions in three phases: in chairs on the same level; with the dominator in the chair and the other on the floor; with the dominator on the floor and the other in the chair. This led to much discussion about what it feels like to be in a position of domination or being dominated, and how important physical position and body language can be in dialogue and communication. (a) Concrete experience

(b) Experiential knowledge
4 We ended the day in small groups discussing concepts of power and strategies for shifting power. The groups then chose a real problem they were addressing in their work, and analysed it using the power frameworks that were introduced. Most used the 'three faces of power' and one group used 'public, private and intimate power'. They looked at the way in which power was involved, and thought about strategies that could be used at different stages to change power relations. Issues they chose to address included NGO accountability, women's participation and street children. (a) Active experimentation

(b) Practical knowledge
5 The next day, small groups completed their work on problem analysis and strategies, and had a 'gallery walk' with short presentations by each group. Most looked at the various ways in which power surfaced, using the frameworks and their own ideas. Some thought about strategies they would need to bring about change, such as public education and awareness raising, working with (a) Abstract conceptualisation

(b) Propositional knowledge 
Table 1 NGO workshop on power and participation in Beirut (cont.)

\section{Learning activity}

(a) Learning cycle/style (Kolb 1984)

(b) Extended epistemology (Heron 1999)

the media, doing advocacy and lobbying, introducing economic empowerment activities, or facilitating processes of internal organisational change.

6 In three smaller groups, we made field visits to local NGOs and community projects in Beirut, bringing the concepts and meanings of power into our interactions. One group asked about the representation of youth within the governance of an organisation that runs youth programmes. Those visiting Palestinian refugees saw their situation as an example of 'invisible power' in which people feel powerless within despite having their basic needs met. An NGO working with migrant women workers from Asia was seen as a case of 'hidden power' because the women are treated as objects and excluded from decision making by the charity. Power analysis was also used to think about strategies for empowerment, such as public education to change the perceptions of Lebanese people toward migrant women, and helping women workers to understand and demand their rights.
(a) Active experimentation
(b) Practical and experiential knowledge

knowledge is often valued above the others, it remains only one dimension or representation of what we know and is strongly shaped by the others.

What do these concepts of learning imply for the study of power? Simply put, if power is multidimensional, we need to 'know' it, not only conceptually but through forms of learning that will allow us to really engage with its multiple dimensions. The process of learning can cycle through a range of activities that permit learners to create their own understandings and experiences of power, in conceptual as well as intuitive and embodied ways, with the senses and emotions, and using artistic and non-dialogical forms of expression. Methods of inquiry might include creative forms of reflective writing (e.g. Richardson 2000), drama and role playing (e.g. Boal 1979), song, poetry, dance, visual art and storytelling. These methods have been successfully combined with more 'propositional' or conceptual forms of learning in adult education and participatory research (Fals Borda 2001), as well as in action research and cooperative inquiry with organisations and communities (Heron and Reason 1997).
While these diverse approaches to learning have long been recognised in certain fields of education and research, it is only recently that higher education has begun to appreciate the value of using more diverse and 'blended' methods of learning to meet the needs of different learners (Biggs 2003; Ramsden 1992), but there is a degree of resistance. Yet within development studies, cyclical and experiential approaches have been successfully used with postgraduate students and in professional training courses. When teaching MA students at IDS for example, we have combined creative writing, storytelling and role plays as a way of engaging with the multiple dimensions of power. We combine these forms of inquiry with conceptual learning, and sequence the process so that students can create their own connections and meanings.

Students in one MA programme, for example, kept learning journals and were asked to use creative writing methods to explore their embodied and internalised experiences of power, and then to try linking these to concepts of power introduced in the course: 
... back to times of feeling powerless, the clearest example for me is that my sense of powerlessness causes a breathless pain in my chest. This occurs whenever I come across cases of women being subjected to domestic violence... This is really an example of the "third face of power", the sociological and entrenched norms and behaviours in society which are intrinsically difficult to change. It is a sensation of having all the weight of the odds of society stacked against you.

When I first came here [to IDS], I felt ... so powerless in terms of language, social-skills, knowledge on development and practical experiences to share ... the internalisation of the feeling of subordination is invisible power. Invisible power can be derived from both the poor people themselves and the external actors such as wealthy high class people in the form of culturally embedded marginalisation and segregation... Addressing invisible power is very tricky. (Student learning Journal entries, anonymous)

\section{Case study: a pedagogy of power}

Principles of cyclical and experiential learning were successfully used in the workshop for NGO leaders in Beirut, as can be seen in this more detailed account. Peter Taylor and I facilitated a journey of discovery over a couple of days that combined personal recall of experiences with creative writing, theatrical enactment, conceptual sense-making and practical application during field visits. The design of this process drew upon Kolb's principles of experiential learning and learning cycles/styles with Heron's ideas of extended epistemologies, as shown in Table 1.

The participants' feedback on this entire learning process was enthusiastic. They enjoyed the reflection and writing, some insisting on reading out what they had written. Their enactments of personal experiences of power were particularly moving and emotional for all of us, and we could have used more time to process them as a group. Some said they valued the movement 'from theory to practice', particularly in the field visits where they could test and apply the frameworks of power analysis.

This feedback affirmed the sort of shift in perspective that we had hoped to achieve in the workshop: the need to understand power in its more subtle and embedded forms, and to revisit the logic behind NGO service delivery and charity by recognising the underlying causes of poverty rooted in relations of power. We also spent time analysing the dynamics of the group itself, addressing some of the power issues that surfaced. We used the frameworks to analyse gender roles and issues of uneven verbal participation in the workshop, and to propose strategies for shifting these dynamics, again linking concepts to practice. Some used the workshop itself as a place to reflect on behaviour, attitudes and identity.

As facilitators, we also used the workshop as an opportunity to reflect on our own power and practice, both as teachers and as outsiders associated with a controversial centre of global power. Space does not permit a full exploration here, but I will share an excerpt from my journal as an example of my own reflective practice:

The power dynamics of being an outside facilitator, and being an American in the Middle East at this moment, has certainly not been lost upon any of us. One participant told me how angry he was at the Americans, but please not to take it personally ... Somehow, we have been able to build a safe context for learning and communication in which national identities have become less important, but they never disappear. Reading the headlines in my hotel room each morning about the bloodbath in Iraq, and then going downstairs to have breakfast with the three Iraqi participants, is surreal. One told me the US troops, who are mostly kids, do not even know why they are there and are now causing more problems than solutions. The Iraqi journalist killed on Monday was a friend. The others are worried that things have turned irrevocably around a dark corner. It feels important to be here, to listen, to try to sense the experience of power in their lives, even if I can never really know it.

\section{Conclusion: power and reflective practice}

Reflective practice is the art of including yourself in your approach to your work, and acknowledging the influence of your position, assumptions and worldview on your understandings and actions. As noted at the beginning of this article, we social scientists have a natural tendency to project our analysis and observation outward. Thus we are interested in how power operates in politics, organisations and society, and how to effect institutional or political change. And whether our understanding of power is rooted in 
agency, structure, or some permutation of these, it is usually about other people's experiences of power. In so doing, we risk losing touch with the way power operates continually in our own lives, private and public.

There are notable exceptions, however, such as approaches informed by feminist thinking, gender analysis, some kinds of anthropology, and by the convergence of these in approaches like feminist anthropology, standpoint theory and other constructivist approaches to knowledge and research. These approaches have in common the idea that our interpretations of data or events will always be influenced to some degree by our own positionality and frames of reference, and that we should be able to make our values and assumptions explicit and even inquire into them as part of the research process. To leave out the self as observer is to deny the very lenses that we use to interpret and understand the world.

With feminism and gender analysis, this value of selfawareness has been carried forward into training methods and programme strategies for working with women, men and communities on gendered power relations, masculinities and femininities (see Harris, this IDS Bulletin). Many empowerment frameworks and methodologies are built upon approaches to strengthening self-awareness, and to questioning dominant social norms and assumptions related to hierarchy. Facilitators of these processes often go through a similar process of critical reflection themselves, as part of their formation.

Most traditions of participatory research and participatory development, similarly, insist that researchers, facilitators, activists and frontline workers should become aware of their own behaviour and attitudes, their assumptions and worldviews, and to notice how these affect their interventions and shape their perceptions of reality (Chambers 1997). Approaches to adult education and transformative learning have also stressed processes of self-reflection or reflexivity (reflection on the self in action). While the focus is facilitating others to do such self-reflection, adult educators and community workers are often trained by going through a similar process themselves.

But why stop there? Methods of reflective practice have become increasingly accepted as a means of professional development in fields of education, health, social work, psychology and management. While not always concerned with power and social change, these are well developed and tested schools of thought and experience in using reflective practice as a professional norm, to enhance learning and performance (e.g. Reason and Bradbury 2001; Bolton 2001; Moon 2004). From these traditions of selfreflection in other fields, many lessons have been learned about what works and what doesn't, including methods for power analysis. Yet there are clearly barriers to using these approaches more widely within international development.

Why is reflective practice not encouraged more extensively among civil servants, NGO workers, social scientists, social movement activists, politicians, leaders, etc.? Many approaches to development are simply not that interested in power, or in challenging power in ways that involve critical self-reflection. This is reinforced by the enduring norm of positivism in social science, which advocates removing the self from the analytical process on grounds of objectivity. As a result, methodologies that involve transformative learning or generating knowledge for social change are relatively marginalised. The development studies disciplines are also somewhat removed from the practical professions noted above, where reflective practice has caught on. And the process of curriculum reform, as explored by Taylor and Boser in this IDS Bulletin, involves contesting deeply institutionalised norms of knowledge and power.

Approaches to self-reflection, reflexivity and power analysis in development studies and practice are therefore, as yet, underdeveloped. Where they do arise, there is a tendency to emphasise conceptual and cognitive forms of sense-making over the other kinds of learning and knowledge discussed here. In so doing, we lose the opportunity to engage with power in all of its dimensions, including in our own thinking, behaviour and practice. One obvious place to begin is with the way we educate ourselves and those who work in development. While there are many barriers to curriculum reform, we know that more innovative approaches to learning are proven and available. These can certainly include creative and multidimensional methods of learning and critical self-reflection that can enable us all to get a better grip on power. 


\section{Notes}

* Many thanks to Rosalind Eyben, Peter Taylor and my fellow learners at Bath University for comments on an earlier draft of this article.

\section{References}

Biggs, John (2003) Teaching for Quality Learning at University, 2nd edn, Maidenhead: Open University and Society for Research into Higher Education

Boal, Augusto (1979) Theatre of the Oppressed, London: Pluto

Bolton, Gillie (2001) Reflective Practice: Writing and Professional Development, London: Paul Chapman Publishing. [Read the Preface and Ch. 1: 'An Introduction to Reflective Practice', xiii-21 (1st edn)]

Chambers, Robert (2002) Participatory Workshops: A Sourcebook of 21 Sets of Ideas and Activities, London: Earthscan

Chambers, Robert (1997) Whose Reality Counts? Putting the First Last, London: Intermediate Technology Development Group (ITDG)

Fals Borda, Orlando (2001) 'Participatory (Action) Research in Social Theory: Origins and Challenges', in Peter Reason and Hillary Bradbury, Handbook of Action Research: Participative Inquiry and Practice, London: Sage

Foucault, Michel (1991) Discipline and Punish: The Birth of the Prison, London: Penguin

Freire, Paolo (1970) Pedagogy of the Oppressed, London: Penguin

Gaventa, Jonathan (2003) 'Power after Lukes: A Review of the Literature', unpublished paper, Brighton: IDS

Hayward, Cynthia (1998) 'De-Facing Power', Polity 31.1: Autumn

Heron, John (1999) The Complete Facilitator's Handbook, London: Kogan Page

Heron, J. and Reason, P. (2001) 'The Practice of Co-operative Inquiry: Research With Rather Than on People', in P. Reason and H. Bradbury (eds), Handbook of Action Research: Participative Inquiry and Practice, London: Sage Publications: 179-88

Heron, John and Reason, Peter (1997)

'A Participatory Inquiry Paradigm', Qualitative Inquiry 3.3: 274-94

Honey, Peter and Mumford, A. (1986) The Manual of Learning Styles, Maidenhead: Peter Honey Associates

Kolb, David (1984) Experiential Learning: Experience as the Source of Learning and Development,
Englewood Cliffs, NJ: Prentice Hall

Lukes, Steven (1974) Power: A Radical View (see also 2nd edn, 2005) London: Macmillan

Marshall, Judi (2001) 'Self-reflective Inquiry Practices', in Peter Reason and Hillary Bradbury, Handbook of Action Research: Participative Inquiry and Practice, London: Sage: 433-9

Mezirow, Jack and Associates (2000) Learning as Transformation: Critical Perspectives on a Theory in Progress, San Francisco: Jossey-Bass

Mezirow, Jack and Associates (1990) Fostering Critical Reflections in Adulthood: A Guide to Transformative and Emancipatory Learning, San Francisco: JosseyBass

Moon, Jennifer (2004) A Handbook of Reflective and Experiential Learning, London: Routledge Falmer

Rabinow, P. (ed.) (1991) The Foucault Reader: An Introduction to Foucault's Thought, London: Penguin

Ramsden, Paul (1992) Learning to Teach in Higher Education, London: Routledge

Reason, P. and Bradbury, H. (eds) (2001) Handbook of Action Research: Participative Inquiry and Practice, London: Sage Publications

Richardson, Laurel (2000) 'Writing - A Method of Inquiry', in N.K. Denzin and Y.S. Lincoln (eds), Handbook of Qualitative Research, 2nd edn, London: Sage

Rogers, Alan (2003) Teaching Adults, 3rd edn, Maidenhead: Open University Press

Scott, James, C. (1992) Domination and the Arts of Resistance: Hidden Transcripts, New Haven: Yale University Press

Stackpool-Moore, Lucy, Taylor, Peter, Pettit, Jethro and Millican, Juliet (2006) Currents of Change: Exploring Relationships Between Teaching, Learning and Development, Brighton: IDS

Taylor, Peter and Fransman, Jude (2004) Learning and Teaching Participation: Exploring the Role of Higher Learning Institutions as Agents of Development and Social Change, IDS Working Paper 219, Brighton: IDS

VeneKlasen, Lisa and Miller, Valerie (2002) A New Weave of People, Power and Politics: The Action Guide to Citizen Advocacy, Oklahoma City: World Neighbors 